\title{
Growth Behavior of Nanocrystalline CrN Coatings by Inductively Coupled Plasma (ICP) Assisted Magnetron Sputtering
}

\author{
Dae-Han Seo and Sung-Yong Chun ${ }^{\dagger}$ \\ Department of Advanced Materials Science and Engineering, Mokpo National University, Jeonnam 534-729, Korea \\ (Received May 8, 2012; Revised July 20, 2012; Accepted August 23, 2012)

\section{유도결합 플라즈마를 이용한 마그네트론 스퍼터링으로 증착된 나노결정질 $\mathrm{CrN}$ 코팅막의 성장거동}

\author{
서대한·전성용 ${ }^{\dagger}$ \\ 목포대학교 신소재공학과 \\ (2012년 5월 8일 접수 ; 2012년 7월 20일 수정 ; 2012년 8월 23일 채택)
}

\begin{abstract}
Nanocrystalline CrN coatings were deposited by DC and ICP-assisted magnetron sputtering on Si (100) substrates. The influences of the ICP power on the microstructural and crystallographic properties of the coatings were investigated. For the generation of the ICP, radio frequency was applied using a dielectric-encapsulated coil antenna installed inside the deposition chamber. As the ICP power increased from 0 to $500 \mathrm{~W}$, the crystalline grain size decreased. It is believed that the decrease in the crystal grain size at higher ICP powers is due to resputtering of the coatings as a result of ion bombardment as well as film densification. The preferential orientation of $\mathrm{CrN}$ coatings changed from (111) to (200) with an increase in the ICP power. The ICP magnetron sputtering CrN coatings showed excellent surface roughness compared to the DC magnetron sputtering coatings.
\end{abstract}

Key words : Inductively coupled plasma, ICP power, Crystal grain size, Preferential orientation

\section{1. 서 론}

6족 원소의 천이 금속질화물 중에서도 $\mathrm{CrN}$ 코팅막은 열적 안정성, 고경도, 내마모성 및 내식성과 같은 우수한 기계적 및 기능적 특성 때문에 주목 받고 있다. ${ }^{1-4)}$ 최근 에는 위와 같은 기계적, 물리적 특성뿐만 아니라 우수한 전기적 특성과 $\mathrm{GaN}$ 와 좋은 격자매칭 특성 때문에 $\mathrm{LED}$ 디스플레이용 버퍼층으로 주목 받고 있다.,6) 이러한 우 수한 특성을 갖는 $\mathrm{CrN}$ 코팅막은 $\mathrm{PVD}$ 와 $\mathrm{CVD}$ 와 같은 다 양한 코팅 방법으로 제작되고 있는데 여러 가지 방법 중 에서도 마그네트론 스퍼터법은 뛰어난 재현성과 밀착력 뿐만 아니라 높은 성막속도와 낮은 기판온도에서도 코팅 이 가능하기 때문에 가장 널리 주목 받고 있다. ${ }^{7)}$ 일반적 으로 경제적 관점에서 보면 성막속도는 빠를수록 유리하 지만 미세구조가 불균일한 주상구조를 나타내거나 다공 성의 코팅막이 생성되기 쉽기 때문에 물성 면에서는 불

${ }^{\dagger}$ Corresponding author : Sung-Yong Chun

E-mail : sychun@mokpo.ac.kr

Tel : +82-61-450-2495 Fax : +82-61-450-2498
리하다. 따라서 미세구조와 물성을 동시에 만족시킬 수 있는 고밀도 플라즈마를 이용한 마그네트론 스퍼터법이 차세대 코팅 방법으로 주목 받고 있다. 코팅막의 제작 시 고밀도 플라즈마를 이용하면 수십 $\mathrm{eV}$ 범위의 에너지 분 포를 가진 이온들이 기판을 향해 이온포격하기 때문에 결 과적으로 치밀한 미세구조의 코팅막을 얻을 수 있다. 본 연구에서는 높은 이온화로 인하여 증착 시 중성원자보다 반응성이 뛰어난 활성 이온들이 저온에서도 쉽게 반응할 수 있으며 이온 에너지의 독립적인 조절과 함께 이온 입 자들에 방향성을 가할 수 있는 장점을 가진 내부 삽입형 유도결합 플라즈마 (Inductively Coupled Plasma, ICP)에 주목하였다.

유도결합 플라즈마 CVD법을 이용하여 고경도의 코팅 막을 제작했다는 연구논문은 기존에도 보고된 바 있으나 이러한 연구의 대부분은 플라즈마가 코팅막의 기계적 물 성에 미치는 영향에 관한 것들이다. ${ }^{8)}$ 따라서 본 연구에서 는 유도결합 플라즈마가 코팅막의 표면과 단면구조와 같 은 미세구조와 결정상 및 우선 배향성과 같은 결정구조 에 미치는 영향에 주목하였다. 특히 이차전지 및 LED 산 업 분야에서 요구되는 수 수십 나노미터 크기의 결정립 
을 갖는 $\mathrm{CrN}$ 코팅기술을 적용하기 위해서는 유도결합 플 라즈마 공정변수에 의한 미세구조 및 결정립 크기를 제 어하는 방법에 대한 철저한 파악이 필요한 실정이다.

따라서 본 연구에서는 코팅 시 유도결합 플라즈마의 이 용과 ICP 전력이 코팅막의 미세구조 및 내부응력 등에 미 치는 영향을 조사하기 위해 종래의 DC 마그네트론 스퍼 터 장치에 내부 삽입형 $\mathrm{RF}$ 코일을 설치하는 형태의 $\mathrm{ICP}$ 마그네트론 스퍼터법을 이용하여 나노결정질 $\mathrm{CrN}$ 코팅막 을 제조하였다. 특히 고이온화 및 고밀도의 유도결합 플 라즈마가 나노결정질 $\mathrm{CrN}$ 코팅막의 몰폴러지 및 결정립 크기와 같은 미세구조적 변화와 우선 배향성, 잔류응력과 같은 결정구조학적 물성에 미치는 영향에 대해 연구하였다.

\section{2. 실험방법}

본 실험에서는 $\mathrm{Si}(100)$ 기판을 사용하였고, 기판 표면의 불순물을 제거하기 위하여 초음파 세척기를 이용하여 아 세톤과 에틸알코올에서 각각 10 분간 세척을 실시한 후 건 조하였다. 본 실험에서 사용한 코팅장비는 ICP 발생을 위 한 $\mathrm{RF}$ 코일을 내부에 삽입하기 때문에 유전체 창이 필요 없고 챔버 내부에 직접 장착할 수 있어 대형화에 유리한 장점을 갖는 내부 삽입형 유도결합 플라즈마를 이용한 $\mathrm{DC}$ 마그네트론 스퍼터법으로 $\mathrm{CrN}$ 코팅막을 제조하였다. 출발원료로는 직경 3", 두께 1/4", 순도 99.995\%의 Cr 타 겟과 초고순도의 $\mathrm{N}_{2}$ 와 $\mathrm{Ar}$ 가스를 사용하였다. 증착시 기 판과 타겟간 거리는 $60 \mathrm{~mm}$ 로 유지하고, 균일한 증착을 위해 기판을 약 $10 \mathrm{rpm}$ 의 속도로 회전시켰다. 챔버의 초 기압력은 로터리 펌프와 터보분자펌프를 사용하여 챔버 초기 압력을 약 $1.3 \times 10^{-3} \mathrm{~Pa}$ 까지 배기시켰으며 진공도의 측정은 이온 게이지와 바라트론게이지를 이용하였다. 또 한 증착 전에 타겟과 기판의 세척을 위해 $\mathrm{Ar}$ 플라즈마를 발생시켜 처리하였다. 얻어진 나노결정질 $\mathrm{CrN}$ 코팅막의 결정구조, 우선 배향성 및 반가폭 등의 분석을 위해 XRD (PAN analytical, X'pert Pro MRD)를 사용하였다. FESEM (S-4800, Hitachi)을 이용하여 코팅막의 표면과 단면 의 미세구조를 관찰하였다. 3 차원적 몰폴러지와 표면 거 칠기 측정을 위해 비접촉식 AFM (Thermo-Microscope, Auto Probe CP Research) 을 이용하였다.

\section{3. 결과 및 고찰}

\section{1. 결정립 크기}

Fig. 1에 DC 및 ICP 마그네트론 스퍼터로 제작한 $\mathrm{CrN}$ 코팅막의 평균 결정립 크기의 변화를 나타냈다. 코팅막의 결정립 크기는 전자현미경에 의한 측정뿐만 아니라 $\mathrm{X}$ 선 회절분석 피크의 반가폭 크기로도 보다 평균적이며 정확 한 계산이 가능한데 일반적으로 반가폭 크기가 클수록 결

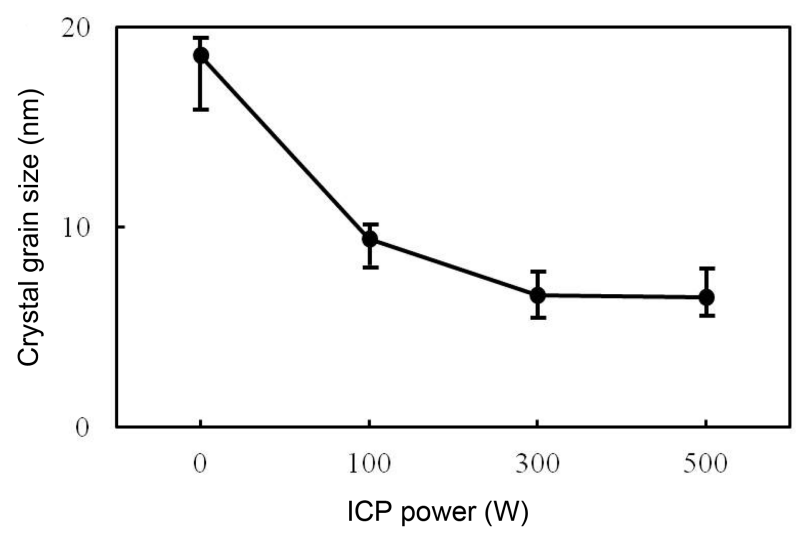

Fig. 1. Crystal grain size of $\mathrm{CrN}$ films deposited by DC and ICP assisted magnetron sputtering (Error bar represents a standard deviation).

정립 크기는 작아진다. 본 연구에서 평균 결정립 크기는 Scherrer법을 이용하여 계산하면 반가폭이 증가할수록 결 정립 크기의 감소를 의미한다. ${ }^{9)}$ 그림에서 알 수 있듯이 코팅 시 유도결합 플라즈마의 이용과 ICP 전력 증가에 따 라 $\mathrm{CrN}$ 코팅막의 결정립 크기는 $17.5 \mathrm{~nm}$ 부터 $6.6 \mathrm{~nm}$ 까지 거의 직선적으로 감소함을 알 수 있다. 따라서 나노 크기 의 입자크기를 갖는 $\mathrm{CrN}$ 코팅막의 미세구조를 제어하는 기술로서 ICP 전력 변화는 매우 중요한 공정변수임을 알 수 있다.

이러한 $\mathrm{CrN}$ 코팅막의 결정립 크기의 나노화 원인으로는 이온 에너지, 이온 플럭스, 잔류 불순물 및 결정학적 집합 조직과 같은 복합적인 요소들의 영향을 들 수 있다. ${ }^{10,11)}$ 본 연구에서는 코팅 시 약 $-100 \mathrm{~V}$ 의 바이어스 전압을 기판 에 인가하였기 때문에 양전하를 띤 스퍼터 금속과 $\mathrm{Ar}^{+}$이 온들의 포격이 코팅에 손상을 입혀 기공을 포함한 다수 의 결함이 막 안에 형성되었다고 사료된다. 이러한 결함 의 밀도는 유도결합 플라즈마 인가에 따라 생성된 고 에 너지의 스퍼터 원자 및 이온들에 의해 더욱더 증가하게 되며 성막 중 기판 위에 반복적인 핵 생성을 유발시킨다. 따라서 스퍼터 중 유입된 $\mathrm{Ar}$ 원자, $\mathrm{Ar}^{+}$이온 및 기공들과 같은 불순물들은 입계에 석출하게 되고 Zener 효과로 인 해 입성장이 제한되기 때문에 이는 $\mathrm{CrN}$ 코팅막의 결정립 나노화 및 형성에 매우 유리하게 작용했다고 사료된다. ${ }^{12}$

\section{2. 결정구조와 우선 배향성}

일반적으로 천이금속 질화물을 코팅 시 화학양론적 조 성을 갖는 질화물뿐만 아니라 비 화학양론적인 조성의 상 도 많이 혼재하여 생성된다고 알려져 있다. ${ }^{13)}$ 예를 들면, $\mathrm{CrN}$ 의 $\mathrm{Cr}_{2} \mathrm{~N}$ 상은 $\mathrm{CrN}$ 의 대표적인 비 화학양론적 화합물 이다. ICP 마그네트론 스퍼터법으로 제작한 질화물 코팅 막의 결정구조는 공정 조건에 따라 달라진다. 따라서 $\mathrm{B} 1$ $\mathrm{NaCl}$ 구조를 가진 단상의 $\mathrm{CrN}$ 코팅막을 제조하기 위해 


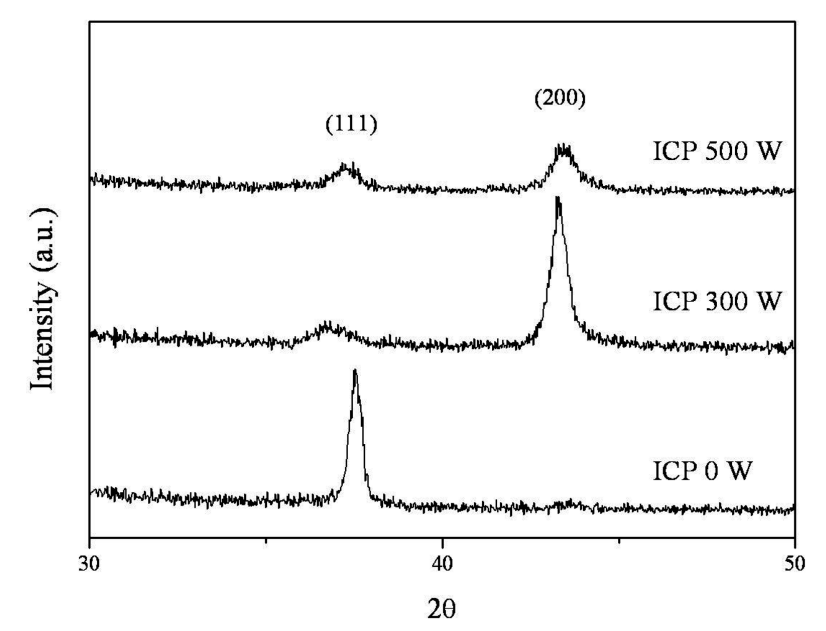

Fig. 2. XRD data of $\mathrm{CrN}$ films deposited using $\mathrm{DC}$ and ICP assisted magnetron sputtering.

서는 질소분압, 플라즈마 밀도, 기판바이어스, 기판온도 등과 같은 공정변수의 조절이 필요하다.

$\mathrm{DC}$ 및 $\mathrm{ICP}$ 마그네트론 스퍼터로 제작한 $\mathrm{CrN}$ 코팅막의 $\mathrm{X}$ 선 회절패턴의 결과를 Fig. 2에 나타냈다. 모든 $\mathrm{CrN}$ 코 팅막에서 단상의 $\mathrm{CrN}$ 화합물의 $\mathrm{X}$ 선 피크가 관찰되고 있 다. 그러나 코팅 시 유도결합 플라즈마의 이용과 ICP 전 력 증가에 따라 $\mathrm{CrN}$ 코팅막의 우선 배향성은 크게 변화 함을 알 수 있다. 예를 들면 유도결합 플라즈마를 인가하 지 않고 $\mathrm{DC}$ 마그네트론 스퍼터로 제작된 $\mathrm{CrN}$ 코팅막의 우선 성장방위는 (111)면이었으나, 코팅 시 유도결합 플 라즈마를 인가하고 $\mathrm{ICP}$ 전력을 증가시키며 제작한 $\mathrm{CrN}$ 코팅막의 우선 배향성은 (200)면으로 변화함을 알 수 있 다. 또한 ICP 마그네트론 스퍼터로 제작된 $\mathrm{CrN}$ 코팅막의 (111)면의 측정 $2 \theta$ 값은 $\mathrm{DC}$ 마그네트론 스퍼터로 제작된 코팅막의 (111)면의 $2 \theta$ 값보다 상당히 저각으로 이동했음
을 명확히 알 수 있다. 이러한 $2 \theta$ 값의 저각으로의 이동 은 코팅막 내부 압축응력의 증가를 시사한다.

$\mathrm{CrN}$ 코팅막의 성장은 타 논문에서 보고된 바와 같이 변형에너지 (strain energy)가 가장 낮은 (111)면과 표면에 너지가 가장 낮은 (200)면 중에서 계의 총 에너지를 낮추 는 방향으로 성장할 것으로 예상할 때 본 연구에서 코팅 된 $\mathrm{CrN}$ 코팅막은 $\mathrm{ICP}$ 전력의 증가에 따라 플라즈마 밀 도 및 이온포격효과의 상승으로 인해 원자의 이동도가 향 상되어 표면에너지가 낮은 (200)면으로 우선 성장하였다 고 사료된다. ${ }^{7,14} \mathrm{CrN}$ 코팅을 적용한 공구강의 기계적 경 도가 (200) 우선 배향성을 지닌 코팅막일 경우, 가장 큰 값을 보이는 결과를 감안하면 본 연구에서 최대 ICP 전 력인 $500 \mathrm{~W}$ 에서 제작된 $\mathrm{CrN}$ 코팅막의 기계적 강도가 가 장 높을 것이라 추측 가능하다. ${ }^{12)}$ 그밖에 특이한 점으로 는 ICP 전력 증가에 따라 (111) 및 (200) 피크의 폭이 증 가하고 있음을 알 수 있다. 이 결과는 Fig. 3에서의 미세 구조 결과와 매우 일치하고 있는데, ICP 전력 인가에 따 라 $\mathrm{CrN}$ 코팅막의 입자크기의 미세화가 진행됨을 알 수 있다.

\section{3. 미세구조}

$\mathrm{DC}$ 및 $\mathrm{ICP}$ 마그네트론 스퍼터로 제작된 $\mathrm{CrN}$ 코팅막의 미세구조를 FE-SEM을 이용하여 관찰하였고 그 표면과 단면사진을 Fig. 3에 나타내었다. 우선 $\mathrm{DC}$ 마그네트론 스 퍼터로 제작된 $\mathrm{CrN}$ 코팅막의 경우 표면에서는 다수의 기 공을 포함한 각형 결정립과 거친 표면이, 단면에서는 기 판 표면부터 막 표면까지 전형적인 다공성 주상구조의 미 세구조가 관찰되었다. 반면 ICP 마그네트론 스퍼터로 제 작된 $\mathrm{CrN}$ 코팅막의 표면의 경우 치밀한 미세 결정립과 매끄러운 표면이, 단면에서는 다공성 주상구조는 사라지 고 기판 표면부터 막 표면까지 매우 치밀한 미세구조가

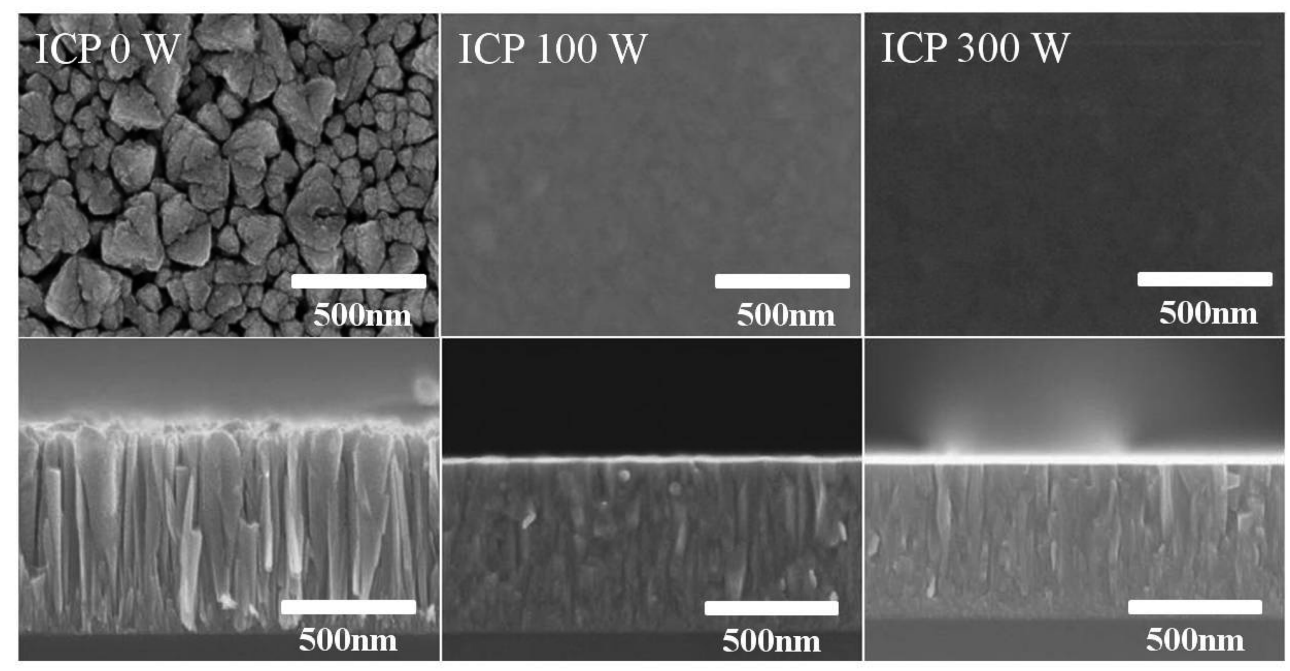

Fig. 3. Surface and cross-section FE-SEM images of CrN films deposited using DC and ICP assisted magnetron sputtering. 

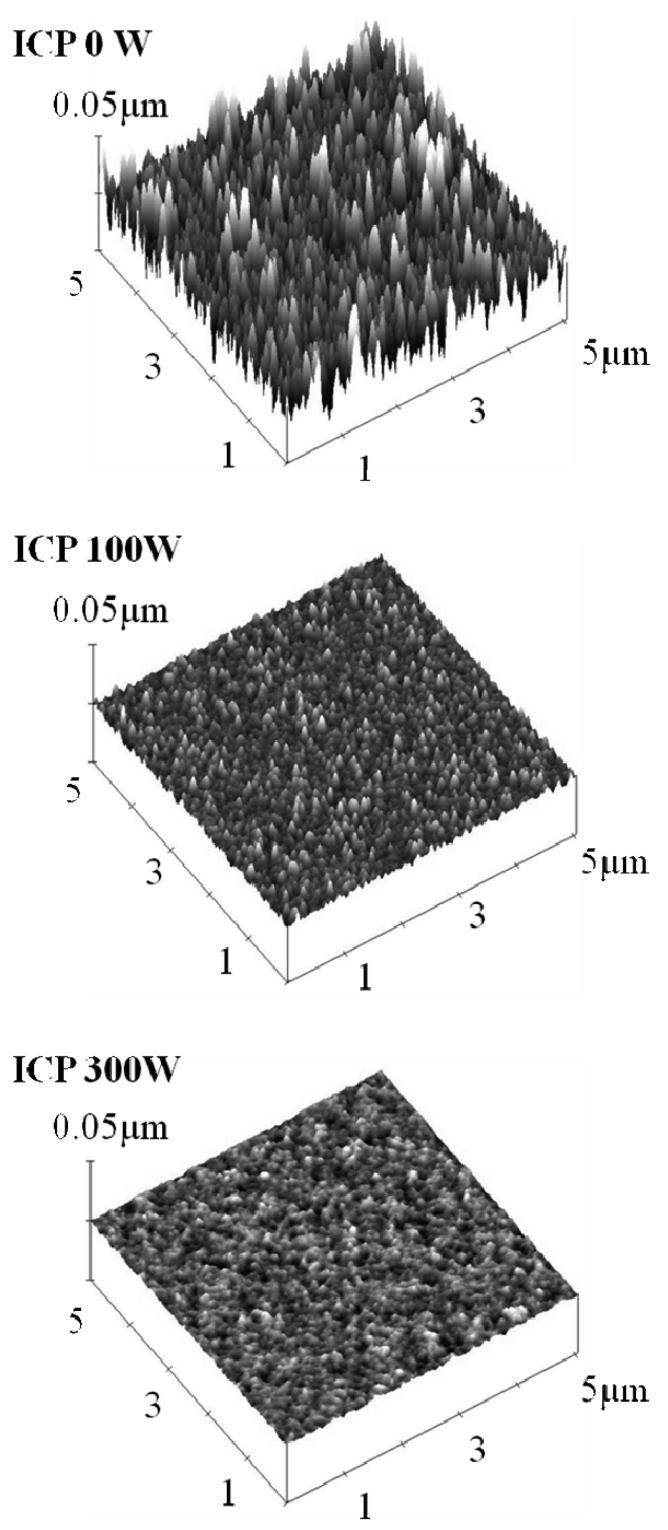

Fig. 4. AFM surface morphologies of $\mathrm{CrN}$ films deposited using DC and ICP assisted magnetron sputtering.

관찰되었다. 이렇듯 고이온화율과 고밀도 플라즈마를 얻 을 수 있는 ICP 마그네트론 스퍼터법을 이용한 결과 스 퍼터된 입자의 이온화율과 고밀도 플라즈마에 의해 원자 의 이동도가 향상되어 코팅막이 형성될 때 공극의 생성 을 줄여 치밀한 코팅막이 형성되었다. 그 결과 $\mathrm{CrN}$ 코팅 막의 평균 결정립 크기는 감소하였고 또한 미세구조는 치 밀해졌다. ${ }^{7,8)}$

또한 본 연구에서는 코팅 시 기판에 $\mathrm{DC}-100 \mathrm{~V}$ 의 바이 어스 전압을 인가했기 때문에 $60 \sim 80 \mathrm{eV}$ 범위의 이온 에 너지 분포를 갖는 다수의 이온들이 기판을 향해 이온 포 격된 것으로 사료된다. 이러한 격렬한 이온포격효과로 흡 착원자에 에너지가 전달되어 흡착원자의 이동도와 핵 생

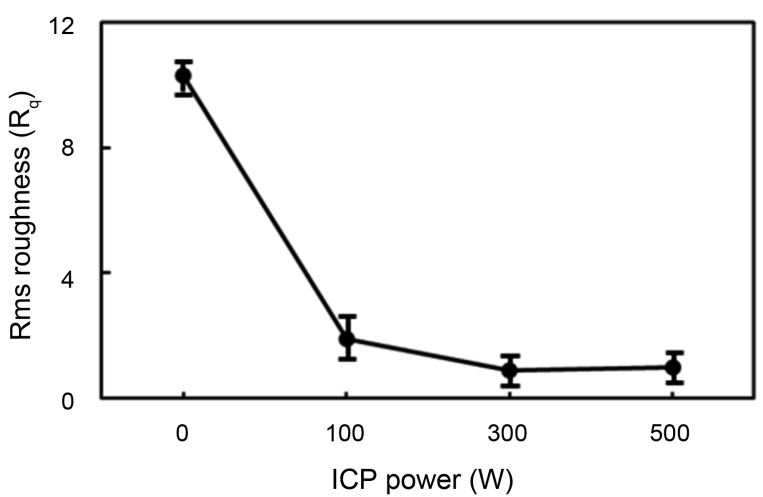

Fig. 5. Surface roughness of $\mathrm{CrN}$ films deposited using DC and ICP assisted magnetron sputtering (Error bar represents a standard deviation).

성 사이트는 증가되었고 결과적으로 결정립 크기의 감소 와 주상 결정립 사이의 기공이 제거되어 코팅막이 치밀 화되었다고 사료된다.

\section{4. 표면형상}

코팅 중 $\mathrm{ICP}$ 전력 증가가 $\mathrm{CrN}$ 코팅막의 3차원적 몰폴 러지와 표면 거칠기에 미치는 영향을 밝히기 위해 비접 촉식 AFM 분석을 실시하였다. Fig. 4는 DC 및 ICP 마그 네트론 스퍼터로 제작한 $\mathrm{CrN}$ 코팅막의 3차원 표면 미세 구조를 나타내고 있다. 코팅 시 유도결합 플라즈마의 이 용과 ICP 전력 증가가 $\mathrm{CrN}$ 코팅막의 rms (root mean square) 표면 거칠기 $\left(\mathrm{R}_{\mathrm{q}}\right)$ 에 미치는 결과를 비교하면 매우 흥미로운 점을 발견할 수 있는데 ICP 마그네트론 스퍼터 로 제작한 $\mathrm{CrN}$ 코팅막의 표면이 종래의 $\mathrm{DC}$ 스퍼터로 코 팅한 $\mathrm{CrN}$ 코팅막보다 매우 평탄하다는 점이다. 예를 들 면 $\mathrm{DC}$ 마그네트론 스퍼터로 제작한 $\mathrm{CrN}$ 코팅막의 $\mathrm{rms}$ 표면 거칠기는 $10.3 \mathrm{~nm}$ 인 반면, ICP $500 \mathrm{~W}$ 에서 제작한 $\mathrm{CrN}$ 코팅막의 표면 거칠기는 $1.3 \mathrm{~nm}$ 로 약 7.9 배 감소하였 다. 이러한 ICP 마그네트론 스퍼터법으로 제작된 $\mathrm{CrN}$ 코 팅막의 치밀하고 평탄한 몰폴러지의 형성과 입자 미세화 의 원인으로는 이온 에너지의 증가에 따른 가속화된 이 온들의 이온포격 효과의 발생과 핵 생성 밀도의 증가를 들 수 있다. 본 연구결과와 유사한 연구논문도 발표되고 있는데 유도결합 플라즈마 PVD법으로 제작된 $\mathrm{TaN}$ 코팅 막에서 ICP 전력 증가가 코팅막의 표면 거칠기 감소에 영 향을 준다고 보고하고 있다. ${ }^{15)}$

\section{4. 결 론}

본 연구에서는 ICP 마그네트론 스퍼터로 나노결정질 $\mathrm{CrN}$ 코팅막을 제조하였으며, 코팅 시 타겟에 인가되는 유 도결합 플라즈마의 이용과 ICP 전력 증가에 따른 코팅막 의 몰폴러지, 결정립 크기와 같은 미세구조적 변화와 우 
선 배향성, 결정상과 같은 결정구조적 변화에 대해 조사 하였다. ICP 전력 $300 \mathrm{~W}$ 가 인가되었을 때 평균 결정립 크기는 약 $6.6 \mathrm{~nm}$ 로 가장 치밀한 코팅막 성장을 나타내었 으며, $0.9 \mathrm{~nm}$ 의 매우 낮은 $\mathrm{rms}$ 표면 거칠기를 나타내었다. $\mathrm{X}$ 선 회절분석 결과, $\mathrm{DC}$ 마그네트론 스퍼터로 제작된 $\mathrm{CrN}$ 코팅막에서는 (111)면만이 ICP 마그네트론 스퍼터로 제작 된 코팅막에서는 (111)면과 (200)면이 모두 관찰되었고 $\mathrm{ICP}$ 파워 증가에 따라 (111)면으로부터 (200)면으로 우선 배향성은 변화하였다. 또한 $\mathrm{DC}$ 마그네트론 스퍼터로 제 작된 $\mathrm{CrN}$ 코팅막의 미세구조에서는 다수의 기공을 포함 한 결정구조가 관찰되었고 ICP 마그네트론 스퍼터로 제 작된 코팅막의 미세구조는 매끄러운 표면과 치밀한 미세 구조가 관찰되었다. 따라서 유도결합 플라즈마의 이용과 $\mathrm{ICP}$ 전력을 조절하여 종래의 $\mathrm{DC}$ 마그네트론 스퍼터보다 우수한 결정립 크기, 몰폴러지, 결정구조 및 우선 배향성 을 갖는 나노결정질 $\mathrm{CrN}$ 코팅막을 제조할 수 있다.

\section{REFERENCES}

1. M. Kang, S. Je, K. Kim, B. Shin, D. Kwon, and J. Kim, "Cutting Performance of CrN-based Coatings Tool Deposited by Hybrid Coating Method for Micro Drilling Applications," Surf. Coat. Tech., 202 [22-23] 5629-32 (2008).

2. S. Shin, M. Kim, M. Kang, K. Kim, D. Kwon, and J. Kim, "Cutting Performance of CrN and Cr-Si-N Coated End-mill Deposited by Hybrid Coating System for Ultra-High Speed Micro Machining," Surf. Coat. Tech., 202 [22-23] 5613-16 (2008).

3. K. Weng, T. Lin, and D. Wang, "Tribological Property Enhancement of CrN Films by Metal Vapor Vacuum Arc Implantation of Vanadium and Carbon Ions," Thin Solid Films, 516 [6] 1012-19 (2008).

4. F. Zhou, K. Chen, M. Wang, X. Xu, H. Meng, M. Yu, and Z. Dai, "Friction and Wear Properties of CrN Coatings Sliding Against $\mathrm{Si}_{3} \mathrm{~N}_{4}$ Balls in Water and Air," Wear, 265 [7-8] 1029-37 (2008).

5. Q. Sun and Z. Fu, “An Anode Material of $\mathrm{CrN}$ for Lithium-
Ion Batteries," Electrochemical. Solid State Lett., 10 [8] A189-93 (2007).

6. S. W. Lee, J.-S. Ha, H.-J. Lee, H.-J. Lee, H. Goto, T. Hanada, T. Goto, K. Fujii, M. W. Cho, and T. Yao, "Lattice Strain in Bulk GaN Epilayers Grown on CrN/Sapphire Template," Appl. Phys. Lett., 94 [8] 082105-082107 (2009).

7. S. Tan, X. Zhang, X. Wu, F. Feng, and J. Jiang, "Comparison of Chromium Nitride Coating Deposited by DC and RF Magnetron Sputtering," Thin Solid Films, 519 [7] 2116-20 (2011).

8. S. J. Jung, K. H. Lee, J. J. Lee, and J. H. Joo, "Study of Chromium and Chromium Nitride Coating Deposited by Inductively Coupled Plasma-Assisted Evaporation," Surf. Coat. Tech., 169-170 [6] 363-66 (2003).

9. B. D. Cullity, and S. R. Stock, "Element of X-ray Diffraction," 3rd. ed., pp. 167-171, Addison-wesley Publishing Conpany Inc, United States of America, 2001.

10. I. Petrov, P. B. Barna, L. Hultman, and J. E. Greene, "Microstructural Evolution During Film Growth" J. Vac. Sci. Tech., A 21 [5] S117-128 (2003).

11. S. Y. Chun, "Microstructure and Mechanical Properties of Nanocrystalline TiN Films Through Increasing Substrate Bias," J. Kor. Ceram. Soc., 47 [6] 479-84 (2010).

12. N. Maazi and N. Rouag, "Consideration of Zener Drag Effect by Introducing a Limiting Radius for Neighbourhood in Grain Growth Simulation," J. Cryst. Growth, 243 [2] 36169 (2002).

13. M. K. Lee, W. W. Kim, S. J. Kim. C. K. Lee, and Y. S. Kim, "A Study on the Characteristics of TiN Film Deposited Reactive Magnetron Sputter Ion Plating," J. Kor. Inst. Surf. Eng., 33 [2] 115-25 (2000).

14. Q. Kong, L. Ji, H. Li, X. Liu, Y. Wang, J. Chen, and H. Zhou, "Influence of Substrate Bias Voltage on the Microstructure and Residual Stress of CrN Films Deposited by Medium Frequency Magnetron Sputtering," Mater. Sci. Eng. B., 176 [11] 850-54 (2011)

15. G. R. Lee, H. Kim, H. S. Choi, and J. J. Lee, "Superhard Tantalum-Nitride Films Formed by Inductively Coupled Plasma-Assisted Sputtering," Surf. Coat. Tech., 201 [9-11] 5207-10 (2007). 